\title{
The Effect of Nanoparticle Concentration on MQL Performance when Machining Ti-6Al-4V titanium alloy
}

\author{
Abdelkrem A. Eltaggaz \\ Advanced Manufacturing Lab (AML) \\ School of Engineering, University of Guelph \\ Guelph, Canada \\ aeltagga@uoguelph.ca
}

\author{
Ibrahim M. Deiab \\ Advanced Manufacturing Lab (AML) \\ School of Engineering, University of Guelph \\ Guelph, Canada \\ ideiab@uoguelph.ca
}

\begin{abstract}
The main purpose of using cutting fluid during machining processes is to reduce the cutting temperature and friction, and to wash away chips from the cutting zone. However, excessive use of conventional cutting fluid negatively influences human health and environment. Therefore, much research has attempted to improve cutting fluid performance with superior tribological and thermal properties, and to reduce the amount of cutting fluid to minimize machining cost and impact on environment. Recently, Minimum Quantity Lubrication (MQL) technique has been widely investigated as a good alternative to flood coolant. Although MQL improves machining results, its removal heat capability still needs to improve. In this paper, in order to enhance the thermal conductive and viscosity of MQL, nanoparticles were dispersed to make nanofluid coolant. Nanofluids have attracted the attention of investigators due to their good high thermal conductivity and ability to remove heat. In this study, the effect of the cutting speed, feed rate, and nanoparticle concentrations on machining titanium Ti-Al6-V4 alloy were investigated by performing ANOVA analysis. The nanofluid coolant was prepared by adding Aluminum Oxide $\left(\mathrm{Al}_{2} \mathrm{O}_{3}\right)$ nanoparticles to base fluid (vegetable oil) at different weight concentrations $(0,2$, and $4 \%$ wt).

The ANOVA analysis found that the nanoparticle concentrations and feed rate had a significant influence on surface roughness. The tool wear was also observed to be affected by nanoparticle concentration significantly. The nanoparticles concentration had a significant impact on the flank wear as it could improve the thermal conductivity and lubrication properties of the cutting fluid and reduce the coefficient of friction between the tool- workpiece and toolchip. In terms of the effect of nanoparticle concentrations, $4 \%$ wt provided better improvements in both surface roughness and tool wear compared to $2 \%$ wt concentration and the pure MQL.
\end{abstract}

Keywords-component; Titanium Ti-Al6-V4 alloy, Tool wear, Surface roughness, Minimum Quantity Lubrication (MQL), Nanocutting fluid

\section{INTRODUCTION}

The effectiveness of machining processes is greatly dependent on the use of cutting fluid to reduce cutting forces and cutting temperature. However, such cutting fluids have negative effects on environment and health. In an effort to eliminate these contrary impacts, many experiments have been conducted using minimum quantity lubrication (MQL) as the main cooling technique. MQL can be also identified as neardry machining (NDM) or micro-lubrication $[1,2]$. Klocke et al. [3] identified the MQL as a cooling technique that uses only a small amount of lubricant, about 3 to 4 orders of magnitude less than flood coolant, at the flow rate of 50 to $500 \mathrm{ml} / \mathrm{h}$. As a result of the lubricant penetration ability into the chip/tool interface, MQL reduces cutting temperature and friction, and extends tool life. Therefore, MQL improves the surface finish of the product. Several investigations have revealed that the MQL technique is a viable alternative to the flood coolant under similar performance parameters $[4,5,6]$. In addition, from the environmental perspective, the MQL method has been shown to be suitable for green machining.

Spraying cutting fluid during machining difficult-to-cut materials, such as titanium, is crucial to reduce the high generated temperature at the cutting zone, thus extending tool life. The MQL technique provides relatively effective machining results, but enhancing its heat removal capacity is still required. MQL with nanoparticles has been suggested to be an effective method for reducing environmental and machine operator hazards due to its good tribological property and antibacterial feature $[7,8]$.

At present, efforts have been made to develop advanced machining processes utilizing less lubrication [10]. For further enhancement, adding nanoparticles into MQL (better known as MQL-nanofluid) may provide much better product quality due to the rolling action of nanoparticles, which could remarkably minimize cutting forces. Also, dispersing nanoparticles into base fluid of MQL would enhance the thermal conductivity and viscosity of the coolant $[10,11]$. Nano-cutting fluids make an important contribution toward meeting the heat dissipation challenge during machining processes as they provide a high practical thermal conductivity value compared to the base fluid [12]. This value can be attributed to the outstanding properties 
of the added nanoparticles (e.g. high heat convection coefficient and thermal conductivity). Moreover, the appropriate dispersion of nanoparticles into the base fluid provides a promising advantage in cutting processes as it helps to reduce the coefficient of friction in the tool-chip interface zone [13]. It has also been revealed that nano-cutting fluids have superior cooling properties due to their effective heat extraction properties [14].

Generally, most research agrees that nanofluids provide higher thermal conductivity in comparison with base fluid; however, determining the appropriate concentration of the nanoparticles is a big challenge. The addition of excessive nanoparticles could result in nanoparticle agglomeration which reduces the lubrication property. Lee et al. [7] stated that the physical parameters such as size and shape of nanoparticles affect their tribological properties. The study was found that determining the appropriate concentration of nanoparticles in base fluid is important to achieve better surface quality and lubrication. Sharma et al. [15] have also observed that an increase of nanoparticle concentration improves the thermal conductivity and viscosity of the nanofluid. Zhang et al. [16] carried out grinding experiments on 45 steel under the jet MQL nanofluid (soybean oil + MoS2) with different mass fraction concentrations $(2,4,6,8$, and $10 \%)$ of $\mathrm{MoS}_{2}$ nanoparticles. It was noted that increasing mass fraction nanoparticle concentration from $2 \%$ to $6 \%$ noticeably reduces the specific grinding energy, grinding forces, and friction coefficient. With further increases in nanoparticle concentration (above than $6 \%$ ), grinding forces, specific grinding energy, and friction coefficient increased. This increase can be attributed to the agglomeration of nanoparticles which cannot lubricate the grinding zone, thus negatively affecting the surface finish. It was concluded that $6 \%$ mass fraction concentration of nanoparticles provided the lowest specific grinding energy, tangential grinding forces, and friction coefficient. Vasu et al. [17] performed turning machining on Inconel 600 alloy under MQL with different volume fractions of $\mathrm{Al}_{2} \mathrm{O}_{3}$ (aluminum oxide) and regular MQL vegetable oil. It was reported that the MQL with 6\% nanoparticle concentration resulted considerable improvement in the surface roughness, tool wear, cutting forces, and cutting temperature compared to MQL with $4 \%$ volume fraction and regular MQL.

\section{EXPERIMENTATION AND METHODOLOGY}

Experiments were conducted by turning titanium Ti-Al6V4 alloy in order to investigate the effects of cutting speed, feed rate, and concentration of nanofluid on tool wear and surface roughness. The tests were performed on a CNC lathe machine using standard coated carbide turning inserts (CNMG120416MR) with a $1.6 \mathrm{~mm}$ nose radius. The machining tests were carried out using MQL nanofluid with different concentrations of volume fraction $(0,2$, and $4 \mathrm{wt} \%)$, at different levels of cutting speed $(120,170$, and $220 \mathrm{~m} / \mathrm{min})$, and feed rate $(0.1,0.15$, and $0.2 \mathrm{~mm} / \mathrm{rev})$ as shown in Table 1 . The depth of cut for each cutting pass was $0.5 \mathrm{~mm}$ with cutting length of $50 \mathrm{~mm}$. Each test was repeated twice for more reliable data, and findings were recorded for maximum flank wear (VB) and surface finish (Ra).

The air-oil mixture of the MQL system was supplied by the stand-alone booster system (Eco-Lubric) with a nominal oil flow rate of $80 \mathrm{ml} / \mathrm{min}$ and air pressure of $0.5 \mathrm{MPa}$. In addition, the vegetable oil ECOLUBRIC E200 was used as a base cutting fluid. This fluid, rapeseed, is environmentally harmless, suitable for industrial application, and has a biodegradability of $90 \%$ in 28 days [18]. The position and the angle of the MQL nozzle were adjusted by experimental observation to avoid being blocked by chips.

For the preparations of the nano-cutting fluid, Aluminum Oxide gamma nanoparticles $\left(\mathrm{Al}_{2} \mathrm{O}_{3}\right)$ were used as nanoadditives. $\mathrm{Al}_{2} \mathrm{O}_{3}$ nanoparticles were selected because of their superior tribological property and anti-toxic aspect. It has 20 $\mathrm{nm}$ average diameter, 95\% purity, and $138 \mathrm{~m} 2 / \mathrm{g}$ specific surface areas. Dispersion of nanoparticles into the base fluid vegetable oil is an important aspect, which effects on thermal conductivity and viscosity of resultant nano-cutting fluid. An ultrasonic machine (AQUASONIC-50HT) was used for 3 hours at $60^{\circ} \mathrm{C}$ to disperse nanoparticles into the base cutting fluid. However, the dispersion of nanoparticles into the base fluid is considered as challenge, due to the strong van der Waals interactions which result in nanoparticle agglomeration, clogging, and sedimentation. Thus, using a physical or chemical treatment such as surfactants is recommended to ensure sufficient dispersion of nanoparticles [19, 20]. Sodium Dodecyl Sulfate (SDS) was used as a surfactant (i.e. $0.2 \mathrm{gm}$ ). Surfactants are believed to make the nanoparticles performance more hydrophilic, and to increase the nanoparticles surface charges, thereby increasing the repulsive forces between the nanoparticles.

In this work, experiments and analysis of variance (ANOVA) analysis was conducted for each of the design parameters and labelled as A (cutting speed), B (feed rate), and $\mathrm{C}$ (nanoparticles concentration) as in Table 2. MINTAB 17 software was used to do design of ANOVA, which was performed to investigate the effect of design parameters on tool wear and machined surface quality. Using the ANOVA, the importance of cutting parameters and nanoparticle concentration with respect to surface roughness and tool wear was studied in order to find out the optimum combination of cutting parameters. All ANOVA analysis were conducted with confidence level of $95 \%(\alpha=0.5)$.

TABLE 1. SCHEME OF EXPERIMENT

\begin{tabular}{|c|c|c|c|}
\hline $\begin{array}{c}\text { Experiment } \\
\text { No. }\end{array}$ & $\begin{array}{c}\text { Speed } \\
(\mathbf{m} / \mathbf{m i n})\end{array}$ & $\begin{array}{c}\text { Feed rate } \\
(\mathbf{m m} / \mathbf{r e v})\end{array}$ & $\begin{array}{c}\text { Nanoparticles } \\
\text { (wt \%) }\end{array}$ \\
\hline 1 & 120 & 0.1 & 0 \\
\hline 2 & 120 & 0.15 & 2 \\
\hline 3 & 120 & 0.2 & 4 \\
\hline 4 & 170 & 0.1 & 2 \\
\hline 5 & 170 & 0.15 & 4 \\
\hline 6 & 170 & 0.2 & 0 \\
\hline 7 & 220 & 0.1 & 4 \\
\hline 8 & 220 & 0.15 & 0 \\
\hline 9 & 220 & 0.2 & 2 \\
\hline
\end{tabular}




\section{RESULTS AND DISCUSSION}

In the current paper, the findings were recorded for max flank tool wear (VB) and surface roughness (Ra). Table 2 describes the max flank wear and surface roughness determined on the cutting tool and machined surface of ADI respectively. The flank wear varied from 0.162 to $0.721 \mathrm{~mm}$, and surface roughness varied from 0.512 to $2.81 \mu \mathrm{m}$. The main effects plots for $\mathrm{Ra}$ and $\mathrm{VB}$ are shown in Figures 1 and 2 respectively. Based on the analysis, low surface roughness was obtained at a feed rate of $0.1 \mathrm{~mm} / \mathrm{rev}$, a cutting speed of 170 $\mathrm{m} / \mathrm{min}$, and a nanoparticle concentration of $2 \mathrm{wt} \%$. Feed rate and nanoparticles wt \% were found to have the greatest impact on surface roughness quality (Figure 1), contributing $46.55 \%$ and $40.75 \%$ respectively (Table 3 ). As known in machining process, the feed rate has a significant effect on the surface roughness. In addition, the impact of the increase in nanoparticle concentration can be attributed to the increase in nanoparticles which can penetrate in the chip and workpiece surface and settle in any micro-grooves or slits in the workpiece surface.

TABLE 2. THE MACHINING PARAMETER LEVELS AND THE OUTPUT MEASUREMENTS

\begin{tabular}{|c|c|c|c|c|c|}
\hline $\begin{array}{c}\text { Experiment } \\
\text { No. }\end{array}$ & A & B & C & $\begin{array}{c}\text { Surface } \\
\text { roughness } \\
(\boldsymbol{\mu m})\end{array}$ & $\begin{array}{c}\text { Maximum } \\
\text { flank } \\
\text { wear } \\
(\mathbf{m m})\end{array}$ \\
\hline 1 & 1 & 1 & 1 & 0.891 & 0.481 \\
\hline 2 & 1 & 2 & 2 & 0.852 & 0.241 \\
\hline 3 & 1 & 3 & 3 & 1.692 & 0.162 \\
\hline 4 & 2 & 1 & 2 & 0.512 & 0.192 \\
\hline 5 & 2 & 2 & 3 & 1.421 & 0.171 \\
\hline 6 & 2 & 3 & 1 & 2.812 & 0.721 \\
\hline 7 & 3 & 1 & 3 & 0.563 & 0.211 \\
\hline 8 & 3 & 2 & 1 & 1.890 & 0.561 \\
\hline 9 & 3 & 3 & 2 & 0.951 & 0.242 \\
\hline
\end{tabular}

In terms of tool wear, the lowest max flank wear (VB) was obtained at a cutting speed of $120 \mathrm{~m} / \mathrm{min}$, a feed of $0.2 \mathrm{~mm} / \mathrm{rev}$, and a nanoparticle concentration of $4 \mathrm{wt} \%$. Generally, the cutting speed significantly affects the tool wear due to the high heat generation at the cutting zone. However, in Figure 2, it can be seen that nanoparticle concentration was found to be the most significant factor, at $90 \%$ contribution (Table 4), with regard to the tool wear. This effect on tool wear behavior was likely because of the good thermal conductivity of the nanoparticle and its ability to penetrate into the chip/workpiece zone, which improve the machining performance, viscous property, and heat removal ability of the nanofluid.

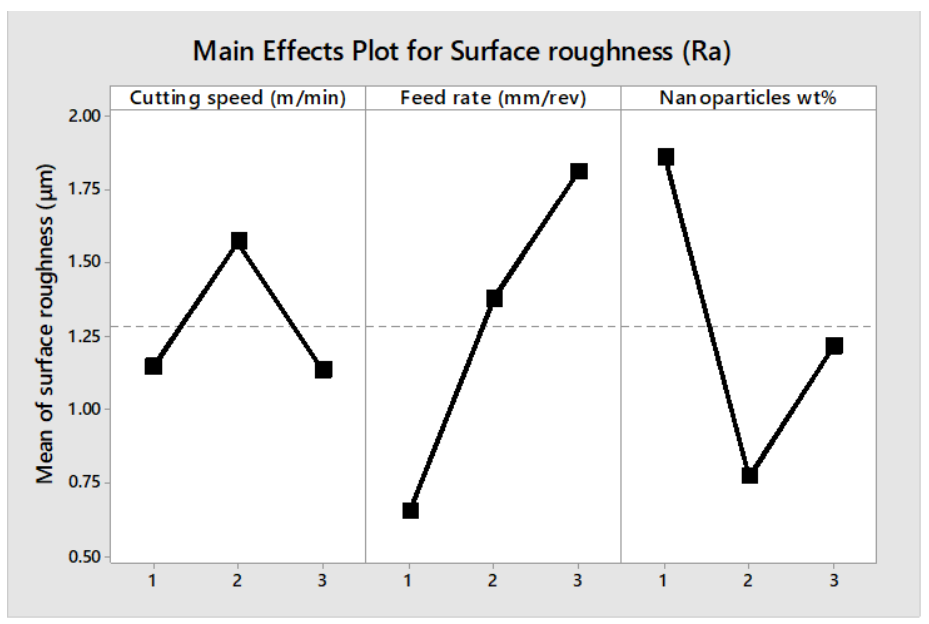

Figure 1. The main effects plot for surface roughness $(R a)$

TABLE 3 ANALYSIS OF VARIANCE FOR SURFACE ROUGHNESS.

\begin{tabular}{|c|c|c|c|c|}
\hline Source & $\begin{array}{c}\text { Degrees } \\
\text { of } \\
\text { freedom }\end{array}$ & $\begin{array}{c}\text { Sum of } \\
\text { squares }\end{array}$ & $\begin{array}{c}\text { Mean of } \\
\text { squares }\end{array}$ & $\begin{array}{c}\text { \% of } \\
\text { contribution }\end{array}$ \\
\hline Speed & 2 & 0.373 & 0.186 & 8.45 \\
\hline Feed & 2 & 2.0551 & 1.027 & 46.55 \\
\hline $\begin{array}{c}\text { Nanoparticles } \\
\%\end{array}$ & 2 & 1.799 & 0.899 & 40.75 \\
\hline Error & 2 & 0.187 & 0.093 & 4.24 \\
\hline Total & 8 & 4.414 & & 100 \\
\hline
\end{tabular}

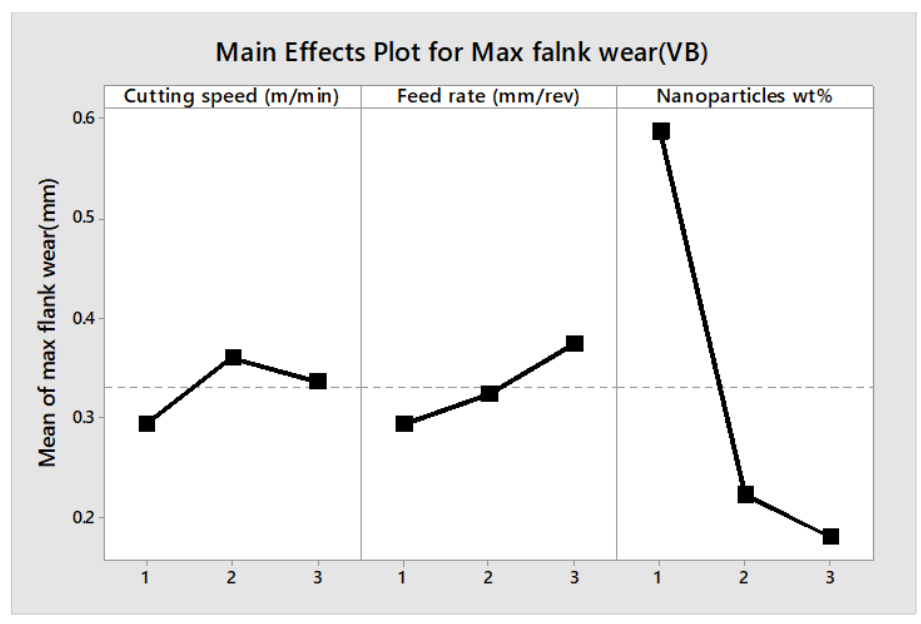

Figure 2. The main effects for the max flank wear (VB) 
TABLE 4. ANALYSIS OF VARIANCE FOR MAX FLANK WEAR

\begin{tabular}{|c|c|c|c|c|}
\hline Source & $\begin{array}{c}\text { Degrees } \\
\text { of } \\
\text { freedom }\end{array}$ & $\begin{array}{c}\text { Sum of } \\
\text { squares }\end{array}$ & $\begin{array}{c}\text { Mean of } \\
\text { squares }\end{array}$ & $\begin{array}{c}\text { \% of } \\
\text { contribution }\end{array}$ \\
\hline Speed & 2 & 0.006 & 0.003 & 2.04 \\
\hline Feed & 2 & 0.009 & 0.004 & 3.00 \\
\hline $\begin{array}{c}\text { Nanoparticles } \\
\%\end{array}$ & 2 & 0.298 & 0.149 & 90.0 \\
\hline $\begin{array}{c}\text { Error } \\
\text { Total }\end{array}$ & 2 & 0.016 & 0.008 & 4.85 \\
\hline & 8 & 0.331 & & 100 \\
\hline
\end{tabular}

\section{CONCLUSION}

In this study, cutting speed, feed rate, and different nanoparticle concentrations (wt \%) in MQL were selected as cutting parameters. According to ANOVA, the feed rate ( 40.75 $\%$ contribution) and nanoparticle concentration (46.55\% contribution) were the most significant parameters that determined the surface roughness on the titanium Ti-6Al-4V alloy. The ANOVA analysis also showed that the nano-fluid at 2 and $4 \mathrm{wt} \%$ concertation of $\mathrm{Al}_{2} \mathrm{O}_{3}$ provided better results than regular MQL in determining surface roughness. The tool wear was also found to be affected by nanoparticle concentration. The analysis indicated that the nanoparticles concentration had a significant influence on the flank wear, at $90 \%$ contribution, as it could enhance the thermal conductivity and lubrication properties of the cutting fluid and minimize the coefficient of friction between the tool- workpiece and tool-chip. Ultimately, it can be concluded that the nano-fluid improves the surface finish and tool life as a coolant during machining titanium TiAl6-V4 alloy. Furthermore, $\mathrm{Al}_{2} \mathrm{O}_{3}$ nanoparticles are improved the machining performance of MQL. However, determining the appropriate nanoparticle concentration needs more investigations.

\section{ACKNOWLEDGMENT}

The authors acknowledge the support of the Natural Sciences and Engineering Research Council of Canada (NSERC) and Ontario centers of Excellence (OCE).

\section{REFERENCES}

[1] B. Boswell, M. Islam, I. J. Davies, Y. R. Ginting and A.Keem, "A review identifying the effectiveness of minimum quantity lubrication (MQL) during conventional machining," International Advanced Manufacture Technology, vol. 92, pp. 321-340, 2017.

[2] J. Dureja, R. Singh, T. Singh, P. Singh, M. Dogra and M. Bhatti, "Performance evaluation of coated carbide tool in machining of stainless steel (AISI 202) under minimum quantity lubrication (MQL)," International Journal of Precision Engineering and ManufacturingGreen Technology, vol. 2, pp. 123-129, 2015.

[3] F. Klock and G. Eisenblatter, "Dry cutting," CIRP Annual
Manufacturing Technology, vol. 46, pp. 519-526, 1997.

[4] A. Eltaggaz, P. Zawada, H. Hegab, H. Kishawy and I. Deiab, "Coolant strategy influence on tool life and surface roughness when machining ADI," The International Journal of Advanced Manufacturing Technology, vol. 1, pp. 1-13, 2017.

[5] K. Sharma, A. K. Tiwari and A. Dixit, "Effects of Minimum Quantity Lubrication (MQL) in machining processes using conventional and nanofluid based cutting fluids: A comprehensive review," Journal of Cleaner Production, vol. 127, pp. 1-18, 2016.

[6] I. Deiab, S. Raza and S. Pervaiz, "Analysis of lubrication strategies for sustanable machining during turning of titanium Ti-6Al-4V alloy," CIRP, vol. 17, pp. 766-771, 2014.

[7] P. Lee, J. Naam , C. Li and S. Lee, "An experimental studyt on microgrinding process with nanofluid minimum quantity lubrication (MQL)," International Journal precission Engineering Manufcturing, vol. 13, pp. 331-338, 2012.

[8] P. Lee, T. Nam , C. Li and S. Lee, "Environmentally friendly nano-fluid minimum quantity lubrication (MQL) meso-scale grinding process using nano-diamond particles, in Manufacturing Automation (ICMA)," in Conference on IEEE, The University of Hong Kong, Hong Kong, China, 2010.

[9] P. Sreejith and B. Ngoi, "Dry machining: machining of the future," Journal Material Process Technology, vol. 101, pp. 287-291, 2000.

[10] A. Sharma, A. Tiwari and A. Dixit, "Progress of nanofluid application in machining: a review," Material Manufacturing Processes, vol. 30, no. 7, pp. 813-828, 2015.

[11] R. Saidur, K. Leong and H. Mohammad, "A review on applications and challenges of nanofluids," Renewable and Sustainable Energy Reviews, vol. 15, pp. 1646-1668, 2011.

[12] S. Hsieh, H. Liu and Y. F. Yeh, "Nanofluids spray heat transfer enhancement," International Journal of Heat and Mass Transfer, vol. 94, pp. 104-118, 2016.

[13] M.Alberts, K. Kalaitzidou and S. Melkote, "An investigation of graphite nanoparticles as lubricant in grinding," International Journal of Machine Tool and Manufacture, vol. 49, pp. 966-970, 2009.

[14] R. Srikant and et al, "Applicabilitynof cutting fluids withn nanoparticle inclusion as coolants in machining," Proceedings of the Institution of Mechanical Engineeering, Part: Journal of Engineering Tribology, vol. 2, pp. 221-225, 2009.

[15] A. K. Sharma, R. Singh, A. Dixit and A. Tiwari, "Characterization and experimental investigation of $\mathrm{Al} 2 \mathrm{O} 3$ nanoparticles based cutting fluid in turning of AISI 1040 steel under minimum quantity lubrication (MQL)," Material today, vol. 3, pp. 1899-1906, 2016.

[16] Y. Zhang, C. Li, D. Jia, D. Zhang and X. Zhang, "Experimental evaluation of MoS2 nanoparticles in jet MQL grinding with different types of vegetable oil as base oil," Journal of Cleaner Production, vol. 87, pp. 930-940, 2015.

[17] V. Vasu and G. Pradeep Kumar Reddy, "Effect of minimum quantity lubrication with $\mathrm{A} 12 \mathrm{O} 3$ nanoparticles on surface roughness, tool wear temperature dissipation in machining Inconel 600 alloy," SAGE Journals, vol. 225, no. 1, pp. 3-16, 2011.

[18] I. Deiab, S. Raza and S. Pervaiz, "Analysis of lubrication strategies for sustainable machining during turning of titanium Ti-6Al-4V alloy," Procedia CIRP, vol. 17, pp. 766-771, 2014.

[19] Y. Hwang, "Thermal conductivity and lubrication characteristics of nanofluids," Current Applied Physics, vol. 6, pp. 67-71, 2006.

[20] H. Zhu and et al, "Preparation and thermal conductivity of suspensions of graphite nanoparticles," Carbon, vol. 1, pp. 226-228, 2007. 